\title{
THE INTERNATIONAL LEGAL PRINCIPLES OF ENVIRONMENTAL PROTECTION IN THE APPLICATION TO THE FORMATION OF THE INTERNATIONAL ENVIRONMENTAL ORGANIZATION OF THE CASPIAN SEA
}

\author{
Araz Ogtay ogly Mursaliev \\ Moscow State Institute of International Relations of the Ministry of Foreign Affairs of Russia, \\ Moscow, Russian Federation
}

\begin{abstract}
Introduction: in the paper, the author aims to analyze the content and legal significance of the international legal principles of environmental protection in the context of the prospects for the formation of an international environmental organization in the Caspian region. The author focuses on the principles that have already been enshrined in the international legal treaties concluded by the Caspian Sea States: the precautionary approach, the "polluter pays" principle, the principle of accessibility of information on marine pollution, and the principle of the ecosystem approach. Methods: the methodological framework for the study is the methods of analysis and synthesis, the empirical methods of comparison, interpretation, as well as such specific scientific methods as the legaldogmatic method and the method of interpretation of legal norms. Results: the results of the study show that the development of the regional environmental protection institutions in the Caspian region should take into account the international legal principles of environmental protection. In particular, based on the analysis of the abovementioned international legal principles, the author justifies the need to give a possible regional interstate environmental organization the functions of monitoring, tracking the causes of harm, the function of a center for collecting, processing and distributing information, as well as coordinating the activities of all existing international and national structures to improve the efficiency of their cooperation. Discussion and conclusions: the development of the regional environmental institutions is impossible without taking into account the international legal principles enshrined in the regional international treaties. The author concludes that it is necessary to apply the content of such principles in the formation of a regional interstate environmental organization.
\end{abstract}

Key words: the Caspian Sea, environmental protection, principles of international law, ecosystem approach, the principle of "polluter pays".

Citation. Mursaliev A.O. ogly. The International Legal Principles of Environmental Protection in the Application to the Formation of the International Environmental Organization of the Caspian Sea. Legal Concept = Pravovaya paradigma, 2021, vol. 20, no. 1, pp. 45-49. (in Russian). DOI: https://doi.org/10.15688/lc.jvolsu.2021.1.6

УДК $341.1 / 8$

Дата поступления статьи: 25.12.2020

ББК 67.91

Дата принятия статьи: 09.02.2021

\section{МЕЖДУНАРОДНО-ПРАВОВЫЕ ПРИНЦИПЫ ОХРАНЫ ОКРУЖАЮЩЕЙ СРЕДЫ В ПРИМЕНЕНИИ К ФОРМИРОВАНИЮ МЕЖДУНАРОДНОЙ ПРИРОДООХРАННОЙ ОРГАНИЗАЦИИ КАСПИЙСКОГО МОРЯ}

\author{
Араз Огтай оглы Мурсалиев \\ Московский государственный институт международных отношений МИД России, \\ г. Москва, Российская Федерация
}

Введение: в статье автор ставит своей целью проанализировать содержание и правовое значение международно-правовых принципов охраны окружающей среды в контексте перспектив формирования между- 
народной природоохранной организации в Каспийском регионе. Автор делает акцент на тех принципах, которые уже получили закрепление в международно-правовых договорах, заключенных государствами Каспийского моря: на принципе предосторожного подхода, принципе «загрязнитель платит», принципе доступности информации о загрязнении морской среды и принципе экосистемного подхода. Методы: методологической основой настоящего исследования стали методы анализа и синтеза, эмпирические методы сравнения, интерпретации, а также такие частнонаучные методы, как юридико-догматический и метод толкования правовых норм. Результаты исследования: результаты проведенного исследования показывают, что при развитии региональных институтов охраны окружающей среды в Каспийском регионе необходимо учитывать международно-правовые принципы охраны окружающей среды. В частности, исходя из анализа вышеперечисленных международно-правовых принципов, автор обосновывает необходимость придания возможной региональной межгосударственной природоохранной организации функций по мониторингу, отслеживанию причинителей вреда, функции центра сбора, обработки и распространения информации, а также координации деятельности всех существующих международных и национальных структур для повышения эффективности их сотрудничества. Обсуждение и заключение: развитие региональных природоохранных институтов невозможно без учета международно-правовых принципов, закрепленных в региональных международных договорах. Автор делает вывод о необходимости применения содержания таких принципов при формировании региональной межгосударственной природоохранной организации.

Ключевые слова: Каспийское море, охрана окружающей среды, принципы международного права, экосистемный подход, принцип «загрязняющий платит».

Цитирование. Мурсалиев А. О. оглы. Международно-правовые принципы охраны окружающей среды в применении к формированию международной природоохранной организации Каспийского моря // Legal Concept $=$ Правовая парадигма. -2021 . - T. 20, № 1. - C. 45-49. - DOI: https://doi.org/10.15688/lc.jvolsu.2021.1.6

\section{Введение}

Реализация положений международных универсальных и региональных (много- и двусторонних) соглашений, формирующих международно-правовой режим охраны окружающей среды Каспийского моря, осуществляется целым рядом международных организаций, конвенций, программ, региональных международных организаций и исполнительных органов отдельных соглашений, а также возложена прикаспийскими государствами на их национальном уровне на множество компетентных государственных органов.

Отсутствие единого центра координации природоохранной деятельности на Каспии приводит к наложению функций, недостаточно эффективному их исполнению, отсутствию реальных механизмов контроля за соблюдением обязательств и т. д.

В своих статьях и работах автор рассматривает различные аспекты проблематики создания региональной межгосударственной природоохранной организации, компетентной в вопросах охраны окружающей среды Каспийского моря [3]. В настоящей статье автор намерен рассмотреть, какие международно-правовые принципы могут лечь в основу ло- гики создания и функционирования такой организации.

\section{Основное содержание}

Первое и наиболее комплексное перечисление принципов международного права, применимых к охране окружающей среды в Каспийском регионе, дано в п. 1.3 Каспийской экологической программы 2006 года. Позднее часть этих принципов легла в основу Рамочной конвенции о защите морской среды Каспийского моря 2003 г. и Протоколов к ней, а также в Конвенции о правовом статусе Каспийского моря 2018 года.

Ст. 4 Тегеранской конвенции указывает в числе общих обязательств ее участников, что стороны обязуются принимать необходимые меры для предотвращения, снижения и контроля загрязнения Каспийского моря; принимать меры для охраны, сохранения и восстановления морской среды, а также использовать ресурсы Каспийского моря таким образом, чтобы не наносить ущерба его морской среде [3]. Среди отраслевых принципов международно-правовой охраны морской среды Каспийского региона названы: принцип принятия мер предосторожности, принцип ответственности сторон, по вине которой произошло 
загрязнение («загрязняющий платит»), а также принцип доступности информации о загрязнении. В настоящей статье будет осуществлена попытка выявить перспективы создания единой межгосударственной организации, компетентной в вопросах охраны окружающей среды в Каспийском море, в контексте реализации отдельных международно-правовых принципов охраны окружающей среды, ужеполучивших прямое или опосредованное закрепление в региональных соглашениях.

В Тегеранской конвенции закреплен «принщип принятия мер предосторожно$c m u$, согласно которому, при наличии угрозы серьезного или необратимого ущерба для морской среды Каспийского моря, ссылки на отсутствие полной научной уверенности не используются в качестве причины для отсрочки экономически эффективных мер по предупреждению подобного ущерба» [3]. Суть принципа предосторожности заключается в том, что меры по предотвращению, ограничению и сокращению загрязнения окружающей среды должны быть исполнены в максимально короткие сроки, причем научные сомнения в необходимости данных действий не могут служить достаточным основанием для задержки. В Конвенции о правовом статусе Каспийского моря 2018 г. смысл принципа предосторожности был дополнительно раскрыт. В частности, в ст. 13 говорится о том, что неоправданные задержки или отказы недопустимы в процессе выдачи разрешений на проведение морских научных исследований, направленных на изучение водных биологических ресурсов, равно как и ресурсов дна и недр. Однако в таком случае должны соблюдаться суверенные и исключительные права Сторон, закрепленные в Конвенции.

Принцุип «загрязняющий платит» о3начает, что виновник в загрязнении окружающей среды обязан нести все расходы, связанные с ликвидацией последствий его действий [2, с. 74]. Данный принцип нашел свое отражение в п. (b) ст. 4 Рамочной конвенции, а также в Конвенции о правовом статусе Каспийского моря 2018 г., где закрепляется ответственность Стороны-загрязнителя за любые действия, повлекшие за собой причинение вреда экосистеме водоема. Прибрежные государства обязуются принимать как само- стоятельно, так и совместно необходимые меры по предотвращению случаев загрязнения, уменьшению исходящего от него ущерба, а также контролю за всеми его возможными источниками. Данный принцип впервые получил свое закрепление в Рекомендациях ОЭСР 1972 г. о руководящих принципах применительно к международным экономическим аспектам природоохранной политики, а позднее - в Декларации Рио-де-Жанейро по окружающей среде и развитию 1992 г. (принцип 16). Важно подчеркнуть, что данный принцип носит экономический характер и является наиболее практически применимым, не декларативным.

Согласно принцииу доступности информации о загрязнении морской среды, закрепленному в ст. 5 Тегеранской конвенции, страны-участницы обязаны предоставить доступ к информации о загрязнении другим прибрежным государствам. Согласно ст. $21 \mathrm{~Pa}-$ мочной конвенции, обмен такими данными между Сторонами должен происходить регулярно [1, c. 23]. Этот принцип нашел свое отражение в деятельности Конференции Договаривающихся Сторон, в частности в уже упомянутых двух Докладах о состоянии окружающей среды Каспийского моря. Прикаспийские государства ведут просветительскую работу, направленную на информирование населения о состоянии окружающей среды, а также поощряют создание неправительственных организаций, занимающихся проблемами экологии. Кроме того, существенным шагом к доступности информации об экологии региона стало присоединение Азербайджана, Казахстана и Таджикистана к конвенции Европейской экономической комиссии $\mathrm{OOH}$ «О доступе к информации, участии общественности в принятии решений и доступе к правосудию по вопросам, касающимся окружающей среды» (далее - Орхусская конвенция), направленной не только на обеспечение доступа к информации, но и на участие граждан в принятии решений по вопросам окружающей среды $[4$, p. 603].

Принции экосистемного подхода широко освещен в ст. 7-11 Рамочной конвенции (посвящены вопросам предотвращения, снижения и контроля загрязнений от различного типа источников); принцип также отражен в Протоколе о сохранении биологического раз- 
нообразия к Рамочной конвенции. Концептуально-правовые основы экосистемного подхода были заложены в Декларации Конференции ООН по проблемам окружающей человека среды в Стокгольме 1972 года. Ключевой вехой в формировании экосистемного подхода можно считать Конвенцию о биологическом разнообразии 1992 года. В тексте Конвенции термин «экосистема» был определен как «динамичный комплекс сообществ растений, животных и микроорганизмов, а также их неживой окружающей среды, взаимодействующих как единое функциональное целое» [2]. На 5-й Конференции Сторон Конвенции о биологическом разнообразии были утверждены 12 базовых принципов экосистемного подхода, включающих в себя необходимость децентрализации органов управления экосистемой ради достижения наибольшей эффективности, долгосрочность поставленных перед ними целей и т. д.

\section{Результаты и выводы}

Во-первых, из изложенного необходимо сделать вывод о том, что в целях реализации принципа «загрязнитель платит» в Каспийском регионе необходимо придание единой межгосударственной организации, компетентной в вопросах охраны окружающей среды Каспийского моря, не только общих функций по мониторингу, но и по отслеживанию причинителей вреда - в координации с компетентными органами государств.

Во-вторых, для целей охраны окружающей среды Каспийского моря необходимо обеспечение государств, хозяйствующих субъектов доступом к информации об экосистеме водоема, о его биологических, химических, геоморфологических характеристиках, загрязнениях, а также о наиболее экологичных доступных технологиях. Представляется, что для координации такой деятельности на уровне региональной межгосударственной организации необходимо наделить ее функциями единого центра сбора, обработки и распространения информации.

В-третьих, необходимо при формировании видения устройства возможной межгосударственной организации учитывать и значение принципа экосистемного подхода. Пред- ставляется, что деятельность такой организации должна быть направлена не на централизацию функций по управлению экосистемой Каспия, а на координацию деятельности всех существующих международных и национальных структур для повышения эффективности их сотрудничества.

\section{СПИСОК ЛИТЕРАТУРЫ}

1. Вылегжанин, А. Н. К учету международноправовых начал экосистемного управления природными ресурсами Каспия / А. Н. Вылегжанин, Е. Е. Андреева, Л. В. Сперанская // Вестник Каспия. - 2002. - № 6. - С. 65-69.

2. Конвенция о биологическом разнообразии 1992 г. - Электрон. текстовые дан. - Режим доступа: https://www.un.org/ru/documents/decl_conv/ conventions/biodiv.shtml (дата обращения: 29.04.2020). - Загл. с экрана.

3. Рамочная Конвенция по защите морской среды Каспийского моря 2003 г. - Электрон. текстовые дан. - Режим доступа: http://www.tehranconvention.org/ IMG/pdf/Tehran_Convention_text_final_rus.pdf(дата обращения: 22.06.2020). - Загл. с экрана.

4. The model of distribution of human and machine labor at intellectual production in industry 4.0 / A. O. Inshakova, E. E. Frolov, E. P. Rusakova, S. I. Kovalev // Journal of Intellectual Capital. - 2020. № 21 (4), pp. 601-622.

\section{REFERENCES}

1. Vylegzhanin A.N., Andreeva E.E., Speranskaya L.V. K uchetu mezhdunarodno-pravovyh nachal jekosistemnogo upravlenija prirodnymi resursami Kaspija [Towards the accounting of international legal principles of the ecosystem management of natural resources of the Caspian]. Vestnik Kaspija [Herald of the Caspian Sea], 2002, no. 6, pp. 65-69.

2. Convention on Biological Diversity 1992. URL: https://www.un.org/ru/documents/decl_conv/ conventions/biodiv.shtml (accessed 29 April 2020).

3. The Framework Convention for the Protection of the Marine Environment of the Caspian Sea 2003. URL: http://www.tehranconvention.org/ IMG/pdf/Tehran Convention text final_rus.pdf (accessed 22 June 2020).

4. Inshakova A.O., Frolova E.E., Rusakova E.P., Kovalev S.I. The model of distribution of human and machine labor at intellectual production in industry 4.0. Journal of Intellectual Capital, 2020, no. 21 (4), pp. 601-622. 


\section{Information About the Author}

Araz Ogtay ogly Mursaliev, Candidate for a Degree, Department of International Law, Moscow State Institute of International Relations of the Ministry of Foreign Affairs of Russia, Prosp. Vernadskogo, 76, 119454 Moscow, Russian Federation, arazmursaliev@gmail.com, https://orcid.org/0000-0002-9358-7423

\section{Информация об авторе}

Араз Огтай оглы Мурсалиев, соискатель кафедры международного права, Московский государственный институт международных отношений МИД России, просп. Вернадского, 76, 119454 г. Москва, Российская Федерация, arazmursaliev@gmail.com, https://orcid.org/0000-0002-9358-7423 